\title{
SUJEITO DO DIREITO UM SUJEITO DO DESEJO - RELATO DE EXPERIÊNCIA
}

\author{
Sarah Cirilo Andujar Hernandes ${ }^{1}$, Mônica Fujimura Leite ${ }^{2}$ \\ ${ }^{1}$ Centro Universitário Católico Salesiano - UNISALESIANO, Lins, SP. ${ }^{2}$ Núcleo de Apoio ao Desenvolvimento da Criança, \\ no Programa Mãe Parananense, Consórcio Intermunicipal do Médio Paranapanema - CISMEPAR. E-mail: \\ mokileite@gmail.com
}

\section{RESUMO}

O conceito de Sujeito do Direito regulado pelas leis sociais que demarcam papéis e lugares sociais e o Sujeito do Desejo representado pela inscrição da Lei primordial - Lei do incesto compartilham da constituição do sujeito em sua totalidade, sendo este marcado pela cultura e por aspectos institucionais, ou seja, a transmissão da Lei e a instituição da pessoa no social, sendo esta a temática principal deste trabalho. Compreender os determinantes de um caso de acolhimento institucional infantil, como elemento norteador para a discussão da construção do sujeito do direito e do sujeito do desejo dentro do conceito lacaniano de função paterna, estrutura o discurso da ancoragem social e simbólica da filiação paterna.

Palavras-chave: Função Paterna. Acolhimento. Direito. Desejo.

\section{LAWFUL SUBJECT A SUBJECT OF DESIRE - EXPERIENCE REPORT}

\begin{abstract}
The concept of a lawful subject regulated by social laws outlines social roles and places, and the wishful subject represented by the inscription of the Primordial Law--the law of incest shares in the constitution of the individual in its totality. This has been made evident by the culture and by institutional aspects, meaning the transmission of the law and the institution of the subject in society, which is the principle theme of this work. To understand determining factors in the face of infant institutionalized shelter, as a guiding factor to the discussion of the construction of a lawful subject and a wishful subject in the laconic concept of parental function, structures the reasoning of the social and symbolical anchorage of paternal affiliation.
\end{abstract}

Key words: Parental function. Institutional Shelter. Lawful. Wishful 


\section{INTRODUÇÃO}

Dentre as atribuições de um técnico de proteção social no âmbito do Sistema Único de Assistência Social (SUAS) estão as de atendimento às famílias em situação de vulnerabilidade e risco social; o acompanhamento de suas fragilidades vinculares e afetivas e potenciais riscos do rompimento destes vínculos; a contribuição para a convivência, reconhecimento e proteção de direitos; o apoio no desempenho da sua função de proteção e socialização de seus membros e o asseguramento do convívio familiar e comunitário. Estas funções partem do pressuposto do reconhecimento do papel do Estado na proteção às famílias e seus membros mais vulneráveis. Dentro dessa prerrogativa as famílias e seus membros são considerados e reconhecidos enquanto Sujeitos de Direitos (BRASIL, 2012).

Nesta realidade de trabalho que foi possível atentar para um crescente aumento de procura de pais e familiares preocupados com seus filhos dentre eles crianças e adolescentes com dificuldades em se submeter as regras e normas sociais. Envolvendo-se em atos transgressores da lei, sendo agressivas e violentas contra os familiares, pessoas a sua volta e seu próprio corpo (automutilação), alguns já estão sob acompanhamento em saúde mental com diagnóstico de Transtorno de Conduta, Transtorno de Déficit de Atenção e Hiperatividade - TDAH, comportamento fóbico e dependência de drogas. Comumente mães, avós, tias ou irmãs (familiares do sexo feminino) procuram apoio e orientação, contudo com maior predominância de mães e avós, sendo alguns destes familiares encaminhados pelo serviço de educação municipal e estadual e Conselho Tutelar, que por insistência ou ameaça de denunciar aos órgãos competentes acabam por aceitar a "sugestão".

Assim este trabalho nasceu inicialmente a partir da reflexão sobre os impactos da presença ou ausência da lei, no que se refere a Lei primordial (interdito do incesto), e as leis sociais e culturais, sobre um sujeito desejante, e sua contribuição para a constituição psíquica e social.

\section{A FUNÇÃO PATERNA E A INSCRIÇÃO DA LEI PRIMORDIAL}

Algumas problemáticas e concepções devem ser consideradas, sendo elas o conceito de FUNÇÃO PATERNA que, segundo Lacan (apud DOR, 2010), destina-se a interditar/proibir a criança como objeto exclusivo do desejo da mãe mantendo este desejo a nível inconsciente.

Para Lacan (apud HURTEL, 2010) o pai real é aquele que alia o desejo a lei, e transmite-a ao sujeito, assim como o lugar simbólico que a lei ocupa. Por outro lado, Lemerle (2010) traz que a constituição do sujeito do desejo humano é ancorado nas relações existentes entre os campos jurídico e psíquico. Com relação ao campo jurídico, este inscreve o humano na ordem da filiação, baseado em sua cultura, suas modalidade e particularidades. No que se refere ao campo psíquico, este sujeito é falado antes de nascer, a partir do desejo dos pais, que determinam Leis de filiação e nomeação, de acordo com um conjunto social ordenado por regras. Assim inaugura-se e transmite-se o NOME deste sujeito, instituído como filho de ou filho da pelo Direito, sendo que este tem a função de representar as leis (âmbito jurídico) e estas têm seu fundamento no campo psíquico, representada pela interdição do incesto que quando internalizadas inscrevem o sujeito no campo jurídico manifestado pelas leis e normas sociais, assim se dá o movimento dialético e ficcional da constituição do sujeito do desejo e do direito.

Diante disto, o sujeito marcado pela sociedade, pelas leis de linhagem e pelo desejo de seus pais, tem possibilitada a condição para sua inscrição social e ancoragem subjetiva. A discussão sobre o Sujeito do Direito e a constituição do Sujeito do Desejo passa pelo conceito de Função Paterna (LACAN, 1999) e pela transmissão da Lei. Entende-se por direito como aquele que inscreve o ser humano na ordem da filiação, baseado em sua cultura, e suas modalidades e particularidades como conceituado por Lemerle (2010).

Nesta pesquisa considera-se a partir de Lacan (2010) Função Paterna enquanto resultando em uma inscrição psíquica, e situada dentro do campo social. Na interdição que a lei paterna 
impõe há uma ordenação para o sujeito na sua relação com o desejo, assim as montagens familiares constituem o Édipo em dois níveis, no simbólico (nome da família) e no imaginário (desejo dos pais). Já com relação ao campo social, há que se considerar ao fundamenta-se em Brito (2008) as mudanças na atualidade quanto o lugar do pai, em seu contexto social, jurídico, econômico e de seu papel em outros ramos sociais.

Ao olhar atentamente para este panorama vê-se a importância em discutir, a partir da ilustração de um caso de acolhimento institucional, as contingências que contribuíram para uma possível falência da lei ou suas distorções na inscrição desta em um sujeito em constituição, elucidar os fenômenos, as implicações e impasses presentes na constituição desse sujeito do direito e sujeito do desejo, ação esta que simbolicamente praticada pela família como um dos agentes fundamentais de proteção e inscrição das regras e normas sociais e culturais.

\section{METODOLOGIA}

O presente artigo, ao considerar os determinantes e características do fenômeno acima mencionado, utiliza como metodologia a Pesquisa exploratória, ao concordar com o Gil (2002) sobre o aprimoramento e compreensão de determinada ideia ou fenômeno. Esta tem como característica a flexibilidade, de modo que possa atentar para os diferentes aspectos referentes ao fato estudado. Dentro do exposto será utilizado como instrumento metodológico da pesquisa o Estudo de Caso utilizando como recurso a análise documental dos documentos institucionais, observação direta e entrevistas realizadas com a criança e sua família, buscando proporcionar a identificação dos fatores que influenciam o fenômeno pesquisado ao explorar situações da vida real que respondam ao questionamento levantado (GIL, 2002, p. 54). Quer-se com esse método explorar e descrever situações da vida real e do contexto investigado.

O caso estudado refere-se a Felipe (nome fictício), uma criança de nove anos que passou por acolhimento institucional dentro da modalidade de Casa, este serviço é prestado pelo município de origem, tendo suas ações subsidiadas pelo CONANDA - Conselho Nacional dos Direitos da Criança e do Adolescente e pelo CNAS - Conselho Nacional de Assistência Social como consta em Brasil (2009) e previsto em Brasil (2002) como sendo medida protetiva, de caráter excepcional e provisório, voltada para o interesse da criança quando seus direitos são ameaçados e violados. Assim devido à situação de abandono e negligência familiar, em situação de rua exposta a risco social.

Foram consideradas para análise a história pregressa da criança, e não o que ocorreu após o acolhimento institucional, para levantar os determinantes sociais e familiares que culminaram no acolhimento.

\section{RESULTADOS}

Há na história de Felipe forte marcas de carências econômicas e educacionais, nível alto de violência e abuso, maus tratos e abandono, o que se assemelha a história de demais familiares com agravante de dependência de álcool e outras drogas e de quadros de transtornos mentais.

Felipe expressava-se sempre com raiva e desconfiança, não obedecia a ninguém, rejeitando a ajuda das pessoas que manifestavam preocupação e interesse pelo seu caso. A criança estava em acompanhamento psiquiátrico, fazendo uso de medicamento que não apresentavam o efeito esperado. Apresentava dificuldades de aprendizagem e no convívio com outras crianças da escola e ao brincar na rua, sendo agressivo e desafiador, com tendência a conduta transgressora da lei.

Antes de vir para o acolhimento institucional, Felipe passava a maior parte do tempo na rua, passando desde a manhã até muitas vezes até a madrugada em companhia de traficantes, usuários de drogas e álcool e pessoas em situação de rua. Segundo fala do próprio Felipe tinha essas pessoas enquanto figuras de referência e admiração. 
Os familiares relatavam que a criança os enfrentava, sendo agredidos por ela física e verbalmente. Meses antes de ser acolhido passou a morar com alguns familiares, pois seus pais afirmavam não conseguir fazer nada para alteração do comportamento e controle de Felipe, dizendo que já não aguentavam o menino, que ele era uma desgraça que não fazia nada direito culpabilizando - o por tudo que estava acontecendo em suas vidas. Diversos familiares da criança, inclusive seus pais, tinham histórico de acompanhamento psiquiátrico e medicalização.

O pai apresenta um histórico de abandono e negligência familiar, fazendo uso abusivo de álcool desde o início da adolescência (após o falecimento de seu pai), apresentando comportamento agressivo e se afastando da família. A mãe de Felipe inicia relacionamento com o pai de Felipe no início da adolescência, sendo colocada para fora de casa, e por volta dos 14 anos engravida dele. Em decorrência das sucessivas agressões físicas e verbais e uso abusivo de álcool do casal, acabam se separa quando Felipe tinha por volta de seis anos.

Neste breve relato do contexto social e familiar da criança, sua vida se inicia com mais alguns agravantes significativos. Devido ao uso abusivo de álcool, negligência e maus tratos por parte da mãe, Felipe é afastado do convívio dela, passando a morar com sua avó materna, e ainda diante dos conflitos entre as famílias acaba sendo afastado de seu pai.

Contudo, mesmo tendo sido legalmente afastado de sua mãe, a avó materna a solicita constantemente quando Felipe apresenta problemas de disciplina. Porém, quando a mãe o corrigia, sua palavra não era mantida. Com dificuldade na convivência com a avó, a criança passa a morar na casa de três familiares diferentes em um curto espaço de tempo, sendo devolvida para avó nas três vezes. Os familiares alegavam não conseguir controlá-lo.

A irmã caçula de Felipe é a preferida da família, por não ser como ele, da avó e outros membros da família, recebendo um lugar de estima na casa de um dos familiares. Assim, Felipe, longe de seus pais, perde a convivência diária com a irmã que passa a morar com outro familiar.

Por fim, a avó materna, alegando estar com "depressão" por causa da criança, pede para que seu neto seja acolhido na instituição, pois não consegui mais cuidar dele.

\section{DISCUSSÃO}

Decorrente do tipo de método empregado, diferentes conceitos puderam ser articulados, dessa maneira, foi possível a partir da contribuição de diferentes autores, observar os caminhos trilhados, para a constituição desse sujeito e seu enlace com a lei, na cultura e sociedade.

Ao elucidar este caso algumas deficiências no nível do cumprimento da função familiar podem ser marcadas: afastamento precoce do pai e ausência de alguém que exerça esta função de forma clara, havendo distorções e duplicidades no nível da inscrição dessa lei primordial, o que compromete a inscrição da criança no mundo do direito e das leis.

Isso comparece, por exemplo, quando, além do distanciamento do pai real, por conflitos existentes entre a família materna e paterna o pai se afastou da criança, quando a mãe exercia sua autoridade, a mesma não era mantida na palavra de nenhum familiar. Além de pela palavra da avó declarar sua impotência como referência de autoridade, ao entregando a criança a três diferentes familiares, que da mesma maneira não assumiram a função de lei e devolveu a criança para avó. $O$ que culminou no ápice da falência da lei quando a avó pede que a criança fosse institucionalizada.

Importante salientar que seu acolhimento se deu não pela solicitação da avó, mas pelo quadro de exposição aos riscos relatados e ao abandono e negligencia familiar.

Em Lacan (1999), o suporte da função simbólica do pai é desde o início dos tempos históricos o que o identifica à figura da Lei, e Lacan (apud HURTEL, 2010) continua ao dizer que o pai real é aquele que alia o desejo a lei, e transmite-a ao sujeito, assim como o lugar simbólico que a lei ocupa. O que fortalece a ideia de que o pai como representante da lei para a criança foi deficiente nesta transmissão, dificultando que ela encontre dentro de sua história recurso 
suficiente que corrobore ao que é solicitado pela família e comunidade - submissão, obediência e disciplina.

Douvile (2010) propõe uma discussão sobre a importância da realidade social na formação da subjetividade, atentando para o grupo e cultura em que este está inserido. Importante sinalizar neste caso, pelo menos em três gerações deste grupo familiar se repete o histórico de abuso de substâncias tóxicas, abandono e negligência dos pais para com os filhos, violência em diferentes graus, transtornos psiquiátricos e separação e rompimento abrupto na relação do referente paterno com o filho. $O$ pai de Felipe aos doze anos iniciou o uso crônico de álcool e deixou o convívio familiar; da mesma forma, Felipe também demonstra comportamentos abusivos e violentos, e também passa a maior parte do dia nas ruas. Além disso, ambos desenvolvem quadro de transtorno de conduta e medicalização.

Assim compreende-se que há ancoragem do sujeito constituído em suas relações sociais e culturais e ainda mais, sua fundação está presa a uma cadeia simbólica antes mesmo que seja abordada sua história estando atrelada a sua linhagem. Como proposto por Lemerle (2010) ao discutir sobre os impasses da filiação, seus efeitos psíquicos e como se articulam com o direito, Felipe na ordem de sua filiação, seus conflitos, história e características familiares está atrelado a cadeia simbólica e transgeracional de sua família.

Minimamente houve transmissão da lei pela família, contudo mesmo diante dos esforços feitos para organizar a criança há duplicidade na comunicação simbólica com a sua realidade familiar e social, ou seja, a falência está na distorção existente na inscrição dessa lei, pois o que é falado pela lei simbólica transmitida pela família entra em conflito com a as leis das regras e normas sociais ocorrendo um desnivelamento da inscrição familiar com a lei, dessa forma a criança transgredi a lei no sentido de não considerar o que é instituído pela sociedade.

\section{CONCLUSÃO}

Ao pesquisar sobre o crescente aumento de crianças e adolescentes com tendências a transgressão da lei, após observar principalmente na prática profissional a partir de relatos de pais e educadores sobre quais os determinantes e fenômenos sociais para a falência da lei na família e sociedade e suas implicações nas crianças e adolescentes alguns entraves dificultaram a pesquisa.

Ao olhar atentamente para casos como o que foi apresentado neste trabalho foi possível refletir sobre algumas mudanças que estão ocorrendo nas famílias no que se refere aos seus papéis e lugares sociais e sobre seu compromisso com esse sujeito que está em processo de constituição psíquica e social. Fato este que não se dá de forma isolada e sim dialética.

A partir do que foi descrito até o momento, o processo de constituição do sujeito tanto do desejo como do direito são indissociáveis, pois assim como o desejo dos pais sobre este sujeito está balizado pela cultura, sociedade e as leis que organizam, a criança quando interditada pela lei primordial encontrará recursos para se submeter as leis relacionada ao campo jurídico e social que anteriormente já foram faladas antes mesmo dela nascer, ao ser determinado pelas leis de filiação que a regem ordenado por um conjunto social de regras.

Quando há distorções na transmissão e inscrição da lei como um todo haverá distorções na conduta e nas relações que se estabeleceram na história deste sujeito, como exemplificado na história de Felipe, é certo que as privações advindas pela desigualdade social e separação de classes e seus efeitos - pobreza, educação medíocre, violência, preconceitos, criminalidade e outros mais devem ser considerados como fatores implícitos na mudança do contexto das famílias e de toda a sociedade. Contudo questões estas tão somente não respondem como não são determinantes unicamente. O humano para se tornar humano ainda necessita de um outro humano que o inscreva no mundo, é este outro que irá inserir o agora sujeito no social.

A relevância deste artigo vem do fato de que existe uma carência em pesquisa que se proponha a investigar sobre a função paterna como correspondente da não apenas da lei 
primordial, mas também das leis enquanto normatizadoras da ordem social. Espera-se com ele instigar novos olhares para essa articulação, bem como o desenvolvimento de um tema importante para a sociedade atual.

Um último fator importante a ser observado é a tendência social de se transferir sua função enquanto família ao estado e seus representantes, vê-se que está havendo uma inversão quanto a figura simbólica e matricial de inscrição da lei. Esta questão não será desenvolvida, por não ser o foco deste artigo, contudo abre-se uma lacuna para futuras pesquisas, a fim de melhor compreensão deste fenômeno.

\section{REFERÊNCIAS}

BRASIL. Estatuto da criança e do adolescente: Lei federal no 8069, de 13 de julho de 1990. Rio de Janeiro: Imprensa Oficial, 2002.

BRASIL. Orientações Técnicas: serviços de acolhimento para crianças e adolescentes. Brasília, 2009

BRASIL. Trabalho Social com Famílias do Serviço de Proteção e Atendimento integral as FamíliasPAIF. Vol. 1. Brasília, 2012.

BRITO, L. M. T. de. Paternidades Contestadas. Belo Horizonte: Del Rey, 2008.

DOR, J. Estruturas clínicas e psicanálise. Rio de Janeiro: Taurus-Timbre, 1991.

DOUVILLE, O. Para apresentar algumas ideias de Pierre Legendre sobre nossa modernidade: palavras de uma psicanalista ocidental. In: ALTOÉ, S. (org.) Sujeito do direito, sujeito do desejo: direito e psicanálise. 3. Ed. Rio de Janeiro: Revinter, 2010. p. 145-157.

GIL, A. C. Como Elaborar Projetos de Pesquisas. 4. Ed. São Paulo: Atlas, 2002

HURSTEL, F. A função paterna, questões de teoria ou das leis à lei. In: ALTOÉ, S. (org.) Sujeito do direito, sujeito do desejo: direito e psicanálise. 3. Ed. Rio de Janeiro: Revinter, 2010. p. 107-133.

LACAN, J.O Seminário, livro 5: as formações do inconsciente (1957-1958). Rio de Janeiro: Zahar, 1999.

LEMERLE, R. M. Sujeito do direito, sujeito do desejo. In: ALTOÉ, S. (org.) Sujeito do direito, sujeito do desejo: direito e psicanálise. 3. Ed. Rio de Janeiro: Revinter, 2010. p. 1-15. 